\title{
Cyber-Crime and Cyber Security Perception in Nigeria
}

\author{
Sarumi J.A. (PhD) \\ Department of Computer Science \\ Lagos State University of Science \& Technology \\ Ikorodu, Lagos State, Nigeria \\ E-mails: sarumi.j@mylasustech.edu.ng \& jerrytechnologies@yahoo.co.uk
}

\begin{abstract}
As the Internet came into widespread commercial use, the nature of computer crimes began to shift. 'While in some crimes, one component of the crime may have been committed using an electronic instrument, in other crimes, the crime as a whole is committed in the online or electronic environment. These crimes, known as cybercrimes, generally occur in the virtual community of the Internet or in cyberspace. As a result of this, all innocent internet users should inculcate the habit of continuously updating their knowledge about the ever changing nature of information technologies. We explore the various types of cybercrimes in Nigeria, their causes, effects and perception of cyber crimes and cyber security among users of the cyberspace
\end{abstract}

Keywords: Cyber-crime, Countermeasures, Fraud, Cyber Criminals, Perception, Cyberspace

Journal Reference Format:

Sarumi, J.A. (2022): Cyber-Crime and Cyber Security Perception in Nigeria. Journal of Behavioural Informatics, Digital Humanities and Development Research. Vol. 8.No. I, Pp 13-22. Available online at https://www.isteams.net/behavioralinformaticsjournal DOI No - dx.doi.org/I0.22624/AIMS/BHI/V8NIP2

\section{INTRODUCTION}

Information technology is vast growing aspect of civilization. Internet especially is an aspect of information technology that enables us to communicate with one another globally irrespective of the country and the continent within a twinkle of an eye. More and more, development strategies are based on the need for developing countries to embrace information technology both as a way to avoid further economic and social marginalization as well as to offer opportunities for both growth and diversification of their economies. The economy of most nations in the world is accessible through the aid of electronic via the internet. Since the electronic market is opened to everybody (which also includes eavesdroppers and criminals), false pretence finds a fertile ground in this situation. The invention of electronic devices such as modern communication hard-wares, internet service and computer systems has been a major landmark in human history.

Some individuals in Nigeria have embraced cyber-crime as a way of life. Many have become rich while some others have been caught by the law (Tade and Aliyu, 20l I). This new crime is denting and drilling holes in the economy of the nation. For example, in a recent report by the Internet Crime Complaint Center which is a partnership between the FBI and America's National White Collar Crime Center, revealed that Nigeria now ranked third among the list of top ten sources of cybercrime in the world (Abdulhamid et al, 20ll). Also the Central Bank of Nigeria (CBN) in its banking sector supervision report revealed that the Nigeria banking sector lost 7.2 billion naira to internet fraud (Ajewole, 20I0). Losing 7.2 billion naira in a developing economy such as ours is not something to be proud about. 
Apart from the destruction cyber-crime does to the economy, it also leads to the erosion of confidence in genuine Nigerian commercial credibility and today many western countries with France taking the lead have moved to deny Nigerian businessmen and women who are legitimate the rewards of e-commerce. France today requires web camera verification for most online business transactions from Nigeria (Longe and Chiemeke, 2018).

In Africa, cybercrime has been indigenously named. For instance, in Nigeria, it is called Yahoo yahoo while the perpetrators are called yahoo boys. In Ghana, it is called 'Sakawa' or 'Yahoo yahoo' 'Faymania' in Cameroon (Oumarou 2017). In Nigeria, the majority of cybercriminals are young people and are found in universities. Yahoo boys are youths involved in cybercrime using electronic e-mails. This social tag originated via the mode employed by yahoo boys in defrauding, which involves sending sinister and deceptive e-mails using hotmail, gmail, yahoo mail and the likes. Alubo (20I I) informs us that the web has created a platform for fraudsters to engage in advance-fee-fraud via the sending of spam e-mails. This act, he notes, is called 419 , and the perpetrators called yahoo boys. They usually make use of free e-mail accounts (e.g., Yahoo, Gmail, Hotmail etc.) to communicate with their targets. Studies have been conducted on the emergence of the yahoo boys subculture the social organization of Internet fraud in Nigeria (Tade and Aliyu 20I I), ICT and perpetration of cybercrime and the cost and attractiveness of cybercrime (Kshetri 2016). In a somewhat similar study conducted in Ghana, Warner $(201 \mathrm{I}, 744)$ reports the use of a klepto-theological paradigm, created to abet the perpetration of Internet crime.

\section{REVIEW OF RELATED LITERATURE}

Many Scholars have conducted researches on the perception of Cybercrime among Nigerian Youths. The following are some of the studies carried out on this Subject matter;

i. Asokhia (2010) in his work, titled "Enhancing National Development and Growth through Combating Cybercrime/ Internet Fraud", carried out a comparative study of young adults perception of cybercrime in two Local Government Area of Edo State. His findings were that cybercrime were very prevalent in two Local Government Areas. More revealing is the fact the impact of television that the young people are aware of and the uncensored video and radio programmes also evolve in one kind of cybercrime or the other.

ii. Adam (2018,) in his work, "The impact of internet crime on development", concludes that the internet is overwhelmingly a powerful tool for development. Paradoxically, the internet is a "double- edged sword", providing many opportunities for individuals and organizations to develop but at the same time, has brought with it new opportunities to commit crime. He argues that the internet presents new challenges to law enforcement in both developed and developing countries. However, developing countries suffer greatly from the activities of internet crime more than their developed counterparts as developing countries have inadequate technology, infrastructure and insufficient law enforcement expertise.

iii. THE MISSPIN AMBASSADORS- the Misspin Ambassadors are a team of twenty four young people who were selected to contribute to sensitizing and creating awareness around cybercrime issues. They are located all over Nigeria and, for the last 12 months, have held various- activities from workshops to media campaigns.

iv. OLUMIDE one of the MISSPIN Ambassadors, in partnership with AIESEC and a 400 Level Student of Computer Science at the University of Abuja, has within the last one year of the MISSPIN campaign engaged young people within and around the University campus in anticybercrime campaigns. He has coordinated a campus -wide rally against cybercrimes while 
also sensitizing internet café operators in the area against the danger of permitting scammers and the sending of scam mails within the precincts of their cyber cafes.

v. Robert who is also a MISSPIN Ambassador, in partnership with Dtalkshop, publishers of Takaii Law magazine, with the support of the Association of Nigeria Authors, Robert has taken the MISSPIN campaign to several Secondary Schools in Lagos and Calabar. Among other campaign efforts, Robert coordinates an anticybercrime media advocacy through the publication of Blingz Magazine, a youthled magazine dedicated to celebrating positive virtues among Nigeria's legitimately enterprising youths.

vi. Ajayi (2016, p.56), he examined cybercrime as a phenomenon that is dysfunctional to the country. Evidence abound that is not only the persons that are duped that suffer for this, the immediate family dependants as well as the society where these victims are from, directly feel the effect of this act. The perpetrators country, also suffers the image problem, even to the extent of losing billions of naira, legitimate investment that is supposed to come to the country. Hence, the companies that ought have established and employed the unemployed Nigerian cannot come to the country. Thus, unemployment continues to rampage the country.

What makes cybercriminals in Nigeria look mystical to people within and around the world is the innovative approach engaged in their operations. They devise numerous ways to be at the imagination of the victims and as security agents discover one of their antics, another one is invented over and over, again and again. Researchers have shown that many operations are professionally organized in Nigeria (Ogwezzy et al, 2012). In most occasions, when potential victims makes attempt to carry out a thorough background check on the proposed business from scammers, they often found out that everything is appealing to common sense. This makes them to believe that the business is genuine. Thus, wealthy foreign investors, medium and even small scale businesses including private individuals are duped millions and billions of dollars and other currencies.

Only in few instances that such background checks would yield positive result for them to discover that the proposed business is a scam and withdraws from the communication link immediately. This success is usually achievable when the fraudsters are in a less organized gang, because a well organized gang always fix every piece together. For Ani (20II), the ICT induced tactics employed by cybercriminals include but not limited to the following; the use of fake cheques, Western Union/Money Gram Wire Transfer, Anonymous Communication, web based email, bad English, email hijacking/friend scam, Short Message Service(SMS), fake websites, invitation to visit a country, purchasing goods and services, vehicle matching service scams, cheque cashing, lottery scam, charity scam, fraud recovery scam, bonavacantia, fake job offers, rental scams, etc. According to (lge and Adomi, 2018), wire transfer via Western Union and Money Gram is often used by cybercriminals because the transaction between the perpetrator and the victim is not traceable and cannot be reversed.

The composition in Western Union is that, once the money is sent, both the source and the destination are concealed against a third party and can never be cancelled. Other means of transferring cash without revealing the sender and the receiver are postal money orders and cashier's checks. Since these routes of wire transfer hide the true identity of internet fraudsters, it is often used to wreck havoc on their targets or victims. The following options have been identified by (Adebusuyi and Adeniran, 20I8) as tactics widely used by cybercriminals. One of the modus operandi of cybercriminals operation is the use of "Bad English". Scammers deliberately fill the content of their communication with faulty grammar and wrong spellings. 
This gimmick enables the potential victim (who may be very educated and fluent in English) to think that he or she cannot be fooled by an illiterate person. Most times, even when they know that the message or information is a scam, they still go ahead to respond and follow up the deals with a false thought of superiority over the scammer, until they are ripped of valuables, money and personal belongings. Web based emails is another method of communication used by cybercriminals because it does not allow for valid identification of information sent to a particular victim. In fact, some of these mails services conceals the sender's IP address very well, making it possible for a cybercriminal to hide his or her identity up to the country of origin. (Agboola et al, 2016) discovered that, because of the diversity of the internet, a cybercriminal can have numerous e-mails account at a particular point in time, and apart from that, they can engage in email hijacking and friend scam involving the hijacking of people's e-mails, and use them to obtain by false pretence.

This is usually done by phishing, key logger or computer viruses in order to have login access to people's emails accounts. A transaction may have been initiated using a yahoo software but could be completed using a fax machine, whenever their victim request for physical documents. Also, in making sure that they are not traceable at all, cybercriminals use prepaid mobile phones linked to a personal mobile or public fax machine. Furthermore, following an advanced stage of cyber criminality, some victims are lured to a town, state or any location to meet a perpetrator who has professed good intentions during the process of communication, then they are kidnapped for a ransom or sometimes killed like the famous story of Cynthia Osokogu who was killed by her Facebook assailant on July 2012 in Lagos State. The criminals usually provide Visa or transport as the case may be. A cybercriminal having successfully duped a victim, recognizes that, the same victim may fall fast in another scam than a potential or a new one, (Akinola et al, 2016).

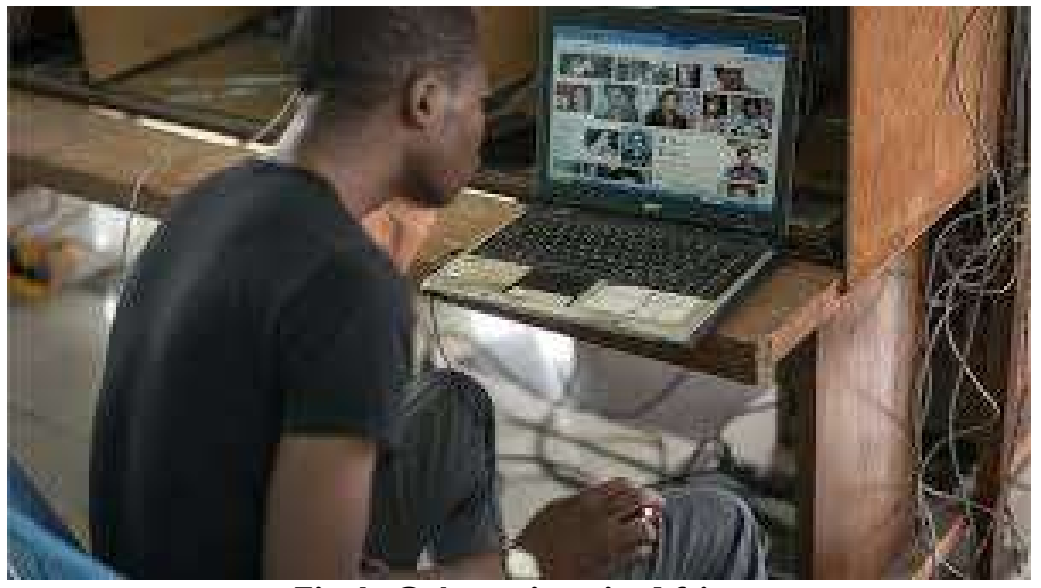

Fig I: Cybercrime in Africa

Source: bbc.com

This is done by reaching out to the victim who has just been duped pretending to be a police officer. Informing the victim that some fraudsters are in the police net, and having heard about this predicament, everything that was stolen from him or her has been recovered. At this point, the success of scamming the victim again is guaranteed because he or she sees the police officer as a third party yet knows much about what was stolen. It is this false thought that will guarantee the release of more money when asked to pay for the retrieval of his or her lost items. 
Only to discover that it is a follow up scam when these items are never released. Others use telephone calls or Short Message Service (SMS) to random victims, sometimes call their names and create familiarity. This method of operation is common in Calabar Metropolis. Victims are usually given attractive business proposals such as the supply of Solar Panels or winning promo alerts etc.

In September, 20I5, an SMS was revolving around Calabar Metropolis and other parts of the country, advising loved ones not to pick calls from a certain number (0I09II), else they will die. This was just a scam SMS to make millions of naira from GSM subscribers. The scammer buys bulk SMS from any of the service providers (MTN, GLO, AIRTEL or ETISALAT) and open a domiciliary account so that all charges on the messages drops into the account. Nigeria has a population of approximately 167million (National Population Commission, 20II), assuming 15 million people circulate this SMS at the cost of N5 per message, you can imagine the millions. Mean while, the scammer had just used a date of $\mathrm{I}^{\text {st }}$ September, 2015 (0I09II) to exonerate himself from legal implications. In 2009, youths in Calabar Metropolis went haywire looking for old pendulum clocks. Cybercriminals offered N500, 000.00 former cury usually found in the clock. It was speculated that this mercury malfunctions the Automated Teller Machine (ATM).

This situation provided a real scare as youths could do anything humanly possible to have this money, until the State Government had to put a stop to the search of these "Abrahamic Clocks". Also, cyber prostitution and child pornography has become the order of the day in Calabar Metropolis and Nigeria as a whole, through social networks such as facebook, 2go, Skype, Whatsapp and black berry pinging. The young generation has seized the opportunity of these social networks to corrupt the communication level of our society in terms of prostitution, pornography, cyber theft, cyber stalking and scamming. The activities of cyber criminals are having a tremendous effect on our communication as a whole. For (Katyal et al, 20I3), cybercrime is a cankerworm that is eating deep and retrogressing the communication sector of the nations, because in every year, millions of people are being duped due to lack of proper information on cybercrimes across the world. Following Katyal perception, the world's population is estimated at 7 billion people, assuming a paltry 3 billion people are ICT compliance, doing businesses, exchanging ideas and innovation on the internet, you can imagine how much will be lost if cyber criminals preys on them.

According to Tunji Ogunleye, a member of Nigeria Cybercrime Working Group (NCWG), the negative uses of the internet by fraudsters in Nigeria out weigh the positive usage. He expresses shock that out of the $60^{\text {th }}$ countries that embraced ICT, Nigeria is the $56^{\text {th }}$ country, yet ranked third among the top ten countries of the world in cybercrime perpetration.(Ogwezzy, et al, 20I2), also noted that, the damage cause by cybercrimes to the Nigerian communication sector is escalating day and night. $\mathrm{He}$ further predicted that cybercrimes if not curb, will have severe negative impact on the Nigerian communication sector. For (Abubaker et al, 2009), because of cybercrimes, Nigeria emails no matter how legitimate are now being blacklisted by the international community. Even internet communication waves from Nigeria are being blocked by other countries internet gateways. Nigerians are now being generally discriminated upon in the world because of the "yahoo boys" syndrome. 


\section{THE CONCEPT OF PERCEPTION}

The central concept of the study was perception. Peoples' reaction to a message depends mainly on their perception of it. This has made perception a core psychological field that draws more attention than other subject matters in psychology. Although much work and studies have been done in the field, psychologists are still unable to arrive at a commonly acceptable definition for perception. (Reynolds et al, 2015) define perception as the organizing principle by which we interpret our sensory input. This goes a long way in that perception is the way an individual reads and acknowledges his environment.

In the same vein, perception is the process of discriminating among stimuli and of interpreting their meaning. Humans have a tendency perceptually as well as cognitively to seek completeness. We read the unsaid and visualize the unseen. We can listen to two people talking about different things, but sooner or later, you have to abandon one person to be able to listen to other, for you to understand $\mathrm{him} /$ her thoroughly. Perception is objective in the sense that it is related to objects, events, issues, situations, etc. The term perception is subject to so many definitions. Oxford Advanced Learners dictionary, $7^{\text {th }}$ edition, defines perception as the way you notice things, especially withsenses. American Encyclopaedia (1994:689) defines perception as a concept in psychology and dealing with a family of meaning. Lindersmith and Strauss referred to it as ways an organism responds to stimuli picked up by the sense organs. In giving clarity to perception, (Dennis and Defleur, 2012) observed that, when a receiver perceives a word, he or she must identify the incoming pattern of physical events known as language symbol rather than other types of event.

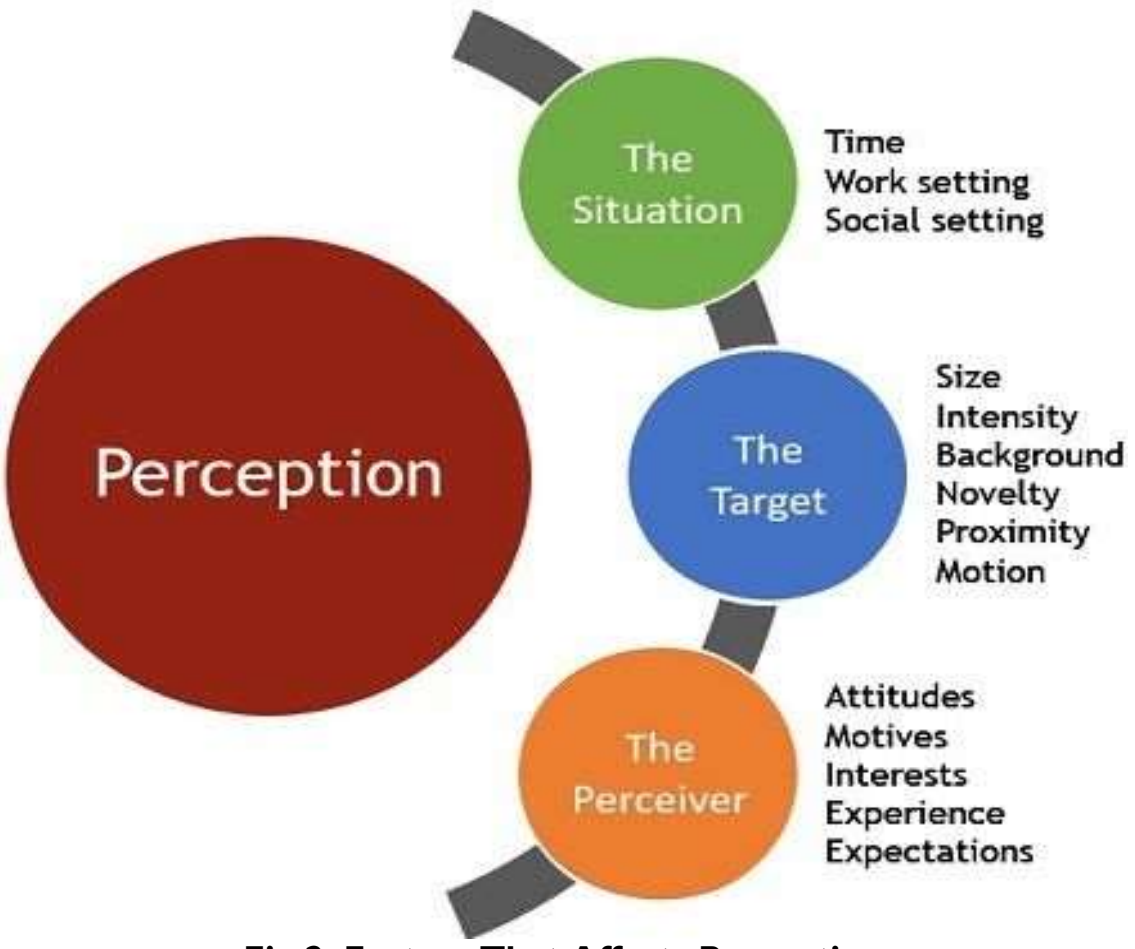

Fig 2: Factors That Affects Perception

Source: https://businessjargons.com/perception.html 


\section{I Social Perception}

Alfred Lindersmith and Anselm Strauss referred to it as ways an organism responds to stimuli picked up by the sense organs. In giving clarity to perception, (Dennis and Defleur, 20I I) observed that, when a receiver perceives a word, he or she must identify the incoming pattern of physical events known as language symbol rather than other types of event. (Folarin et al, 2013) explains that perception depends on complex variables such as psychological disposition, past experiences, needs, cultural expectations and social relationship.

In other words, each of us tends to perceive and then decide communication message in the light of our previous experiences and current disposition, needs, belief and memories, (Alfred and Anslem, 2013) identified the processes affecting perception in the following variants. Selectivity of perception: you see what you want to see while you neglect others. Frequency of previous experiences with particular stimulus and responses, which affects present stimuli.

- Experience with stimuli and responses that have been positively or negatively reinforced.

- The contemporary factor prevailing at the moment of perception, such conditions include, hunger, fatigue or anxiety, which may affect what, is perceived. (Folarin et al, 20l3) also noted that selective interpretation of a given message causes an undue internal dissonance. That is, the receiver of the message may decide to forget the message.

\subsection{Perception and Image}

An image is a set of beliefs about an object, (krechtetal et al, 2016). According to Oxford Advanced Learners dictionary, $7^{\text {th }}$ edition, (743), image is the impression that a person, an organization or a product, etc. gives the public. A person's image of an object does not necessarily reveal his attitude towards an object. However, the image of an object varies from person to person. This is largely due to the person's beliefs, needs and past experiences with the object. Also, images vary in their clarity and complexity. People at times, or have fuzzy or other related impressions.

\subsection{Perception of Cybercrime committed by Nigerian Youth}

Various scholars have examined the term "perception. People perceive things in a way that accord to their beliefs, interests, motives, needs and learning. According to (Obono et al, 2018), cybercrime describes "those criminal acts either committed in cyberspace, such as various forms of identity theft and bank fraud, or acts that have a physical component and are simply facilitated by the use of internetbased tools". Such acts commonly include distribution of fraudulent emails, and pornography on the internet. He further notes that cybercrimes are illegal activities perpetrated by one or more people using the cyberspace through the medium of networked computers, telephones and other information and communication technology equipment.

There is hardly any crime committed in the world today that does not have cybercrimes undertone, because of high dependence on modern technology. According to (Oketola et al, 2019) some young people use the web for information on current issues in health, education, politics, researches, sports, and for personal development as well as building skills. While others, misuse it for unconstructive activities. It is perceived by many, that what constitutes young people's involvement in cybercrimes largely depends on their low level of moral standards, peer pressure, corruption, greed, poverty, and get-rich-quick-syndrome, lack of parental guidance and lack of jobs. 


\section{THE INTERNET AS A MEDIUM FOR COMMUNICATION}

The internet allows society to communicate with people of all nationality and ages from every country in the world. It has provided the facilities its users most appreciate like the news on the web. Anyone with the skills can post any information on the web, Individuals who post information and use the internet do not need licenses or permission which is the reason for such growth globally. The internet is changing the way we communicate but most importantly how we receive and transmit information. "The internet is changing media use patterns and the lifestyles of millions of people who have grown to rely on it as a source of entertainment, information, and communication. People are discovering this interactive medium, and with it, new ways to access information and to communicate with others. The internet is becoming increasingly important in the lives of many people around the world. I cannot emphasize the importance of the internet as many people not only use it to communicate but also for businesses either to advertise or to partner up with other businesses for parts of the world.

Tim Berners -Lee created the World Wide Web as a means of sharing scientific information, he wrote the web software as an internet-based hypermedia initiative for global information sharing. "The internet comprises various text only resources and the World Wide Web, which presents information in text, graphic, video, and audio formats. It is this burgeoning internet resource that has captured the attention of millions, and since it is also having a great impact on traditional mass media". Traditional mass media allows a "one to many" model of communication where an individual can speak once, but to many people, these are broadcast, satellite television and radio. However the internet allows a 'many to one' model which is a cross between mass broadcasting and interpersonal communication, this allows people to choose the information they want and to ignore the rest. The ways in which we communicate are via Email and Chat Forums, Email was developed in the early days of the internet and is currently the most popular, efficient and widely used globally as a means of communication.

It keeps people connected whether for business or pleasure, the 'boundaries of email use inevitably overlap with our other metaphors for thinking about the information infrastructure. Chat forums allow the exchange of live conversations. Many argue that "it is a new mass medium that delivers mass messages to a mass audience of web users, thus following the traditional one-to-many model of communication. For example, each web user who visits the CNN interactive page has access to the same information as everyone else regardless of their personal beliefs, attitudes, or opinions. (Kaye and Medoff, 20I I) on the other hand new technologies are developed in order for individuals to select information. This way the internet is seen as a new interactive medium rather than a mass medium. "The internet crosses the boundaries that have traditionally delineated the three modes of communication: mass (one to many), interpersonal one to one and computing many to one. By virtue of its nature, the internet allows for all three types of communication, with a fourth communication mode, many to many emerging.

The internet is a vehicle for interpersonal communication and interactivity, mass delivered messages, and information storage, processing, and retrieval. It is a true communication phenomenon and one that allows many forms and styles of communication". (Kaye and Medoff, 20I I).The internet changes the way we receive and provide information, we turn to the web for, information, news and entertainment, it is now common for television to be on the web as it enhances ones way of viewing television rather than just using a computer. We now have our favorite shows and news posted on the internet; it is set up so if we miss an episode we can always find it online with extras. This has increased the amount of internet users as it is convenient and comfortable. 
"Without the time and space constraints that plague traditional media, web authors and designers are free to expand their offerings and produce web-only material and web versions of traditionally delivered fare. The web is exploding with sites that complement traditional offerings but also offer unique content found elsewhere. Electronic magazines and newspapers and online soap operas and talk shows are just a few examples of original content. The web is a unique medium where original and adapted content live side by side". Communication through the web can only be possible with the use of internet. "Internet as a global communication network are dominated by individuals and organization based in countries" however globalization is the force behind this, as the process has allowed internet to be a communication and information technology. In late modernity globalization promotes the general good in any practical sense. "The Internet is being used to achieve a great control over globalizing influences and globalised processes of communication in the world today. "The internet is thus creating new opportunities for developing local sensitivity on a global scale, helping aid to remedy problems of global inequality rather than exacerbate them (Slevin, 20I0).

Another method of communication, where you can access the internet wirelessly is mobile phones, mobile phones are very popular world wide as they are used by everyone not only to communicate by voice or text messaging but other features like surfing the web on your phone. Wi-Fi technologies bring alternative modes of accessing the internet; it has provided internet access to mobile phones users in poor countries where the technology is not popular. "Horizontal networks of communication and multiple sources of information on a global scale create the possibility of a largely autonomous diffusion and exchange of information, ideas and initiatives. (Castells et al, 2017). In the 1990's the internet contributed to the growth of surveillance which then became a Global Sphere. The growth of the internet has provided new opportunities for surveillance where it is seen in the spheres of workplace, military, government and for personal use.

To end the internet would forever have an impact in our lives, it would enhance the way we live and communicate to others, and it would enable us to create identities we share with the world. There are thousands of ways to transfer information and data; we have been giving opportunities to create businesses on a global scale, where we can communicate with business owners in other countries that might enhance ones business. With a click of a button one can access anything on the web which is what makes the internet a phenomenal. With the internet changing lives and developing as a form of information society it also plays a role in exposing people especially politicians and celebrities. Cyberspace is changing how we live our lives and one has to be careful especially living in the public eye.

It was cyberspace that exposed the scandal about Bill Clinton; the story, posted on the web to audiences, changed how audiences perspective on him, as well as the scandals about Tiger Woods' which also spiralled over the web, this could be seen as a negative to the internet and what it comes with. "Technological change seems to have its own logic, which we may perhaps protest about or even try to block, but which we appear to be unable to alter fundamentally. (Kitchin et al, 20I I) "they are developed at any one time and placed in accord with a complex set of exciting rules or rational procedures, institutional histories, technical possibilities, and last, but not least, popular desirers" (Kitchin et al, 20II) 


\section{CONCLUDING REMARKS}

The growing danger from crimes committed against computers, or against information on Computers, is beginning to claim attention in national capitals. In most countries around the world, however, existing laws are likely to be unenforceable against such crimes. Self-protection, while essential, is not sufficient to make cyberspace a safe place to conduct business. The rule of law must also be enforced. Countries where legal protections are inadequate will become increasingly less able to compete in the new economy. As cyber crime increasingly breaches national borders, nations perceived as havens run the risk of having their electronic messages blocked by the network.

\section{REFERENCES}

I. Abdulhamid, S.M, Haruna, C. and Abubakar, A. (20II) Cybercrimes and the Nigeria Academic Institution Networks. The IUP Journal of Information Technology. Vol VII No I. pPII.

2. Alubo, O. (20II). The Public Space in Nigeria: Politics of Power, Gender and Exclusion. Africa Development XXXVI, I, 75-95.

3. Ajewole, A. (2010). Curbing Cybercrime in Nigeria. Fighting the Masked Enemy and Promoting Productive Alternative for the Youth. Retrieved October 8, 2011 from http/www.primopdf.com.

4. Anah Bijik Hassan, Funmi David Lass \& Julius Makinde, (2013). Cybercrime in Nigeria: Causes, Effects and the Way Out. ARPN Journal of Science and Technology.

5. Coomson, J. (2009). Cyber Crimes in Ghana. Ghanaian Chronicle, 4 October 2016, from http://allafrica.com/stories/2006/0040856.html

6. Dr. Martins, J. Oni, (2013). Cyber Crime in Nigeria: The Implication on our Economy and Social Image. Retrieved from http://www.acta-pac.org on the $17^{\text {th }}$ of July, 2017.

7. Folashade B. Okeshola \& Abimbola K. Adeta, (2013). The Nature, Causes and Consequences of Cybercrime in Tertiary Institutions in Zaria-Kaduna State, Nigeria. American International Journal of Contemporary Research Vol. 3 No. 9

8. Jaishankar, K. (2010). The Future of Cyber Criminology: Challenges and Opportunities. International Journal of Cyber Criminology 4, 26-3I.

9. Kshetri, N. (2016). The Simple Economics of Cybercrime. IEE Security and Privacy. Retrieved from www.computer.org/security

10. Longe O.S. and Chiemeke S.C. (2018). Cyber Crime and Criminality in Nigeria. What Roles are Internet Access Points in Playing? European Journal Social Sciences Vol 6, No 4, pp I32-139

II. Melvin, A. O., Ayotunde, T. (20II). Spirituality in Cybercrime (Yahoo Yahoo). Activities among Youths in South West Nigeria. Google books.

12. Oumarou, M. (2007). Brainstorming Advanced Fee Fraud: 'Faymania'-the Camerounian Experience. In N. Ribadu, I. Lamorde and D. W. Tukura (Eds.). Current Trends in Advance Fee Fraud in West Africa, pp. 33-34. Nigeria: EFCC.

13. Tade, O. and Aliyu, I. (20II). Social Organization of Cybercrime among University Undergraduates in Nigeria. International Journal of Cyber Criminology 5, 860-875.

14. Warner, J. (201 I). Understanding Cyber-Crime in Ghana: A View from Below. International Journal of Cyber-Criminology 5(1), 736-749. 